\title{
A non-synonymous polymorphism in NBSI is associated with progression from chronic hepatitis B virus infection to hepatocellular carcinoma in a Chinese population
}

This article was published in the following Dove Press journal:

OncoTargets and Therapy

\author{
Ya'nan Zhen, 1,2,* Ruixue \\ Xiao, ${ }^{3, *}$ Xing Chen, ${ }^{4}$ \\ Changjin Yuan, ${ }^{5}$ Yanlai Sun, ${ }^{6}$ \\ Jie $\mathrm{Li}^{\prime}$ \\ 'Department of General Surgery, \\ Qianfoshan Hospital, Shandong \\ University, Jinan, ${ }^{2}$ Department of \\ General Surgery, Affiliated Hospital \\ of Shandong Academy of Medical \\ Sciences, Jinan, ${ }^{3}$ Department of \\ Pathology, Affiliated Hospital of \\ Shandong Academy of Medical \\ Sciences, Jinan, ${ }^{4}$ Institute of Basic \\ Medicine, Shandong Academy of \\ Medical Sciences, Jinan, ${ }^{5}$ Department \\ of Clinical Laboratory, Affiliated \\ Hospital of Shandong University of \\ Traditional Chinese Medicine, Jinan, \\ ${ }^{6}$ Department of Gastrointestinal \\ Cancer Surgery, Shandong Cancer \\ Hospital Affiliated to Shandong \\ University, Shandong Academy \\ of Medical Sciences, Jinan, \\ People's Republic of China \\ *These authors contributed equally \\ to this work
}

Correspondence: Yanlai Sun Department of Gastrointestinal Cancer Surgery, Shandong Cancer Hospital Affiliated to Shandong University, Shandong Academy of Medical Sciences, 440 Jiyan Road, Jinan 250I I7, People's Republic of China Email sunyanlai@I26.com

Jie Li

Department of General Surgery, Qianfoshan Hospital, Shandong University, 16766 Jingshi Road, Jinan 2500 I4, People's Republic of China Email lijie0503@I26.com
Purpose: Nijmegen breakage syndrome 1 (NBS1) has a vital role in DNA double-strand break (DSB) repair, functioning as a sensor to identify and repair DNA damage and maintaining genomic stability by participating in the intra-S-phase checkpoint. Polymorphisms of NBS1 have been investigated in multiple cancers with variable results. To our best knowledge, no previous study has focused on the association between NBS1 single-nucleotide polymorphisms (SNPs) and hepatitis B virus (HBV)-related hepatocellular carcinoma (HCC).

Patients and methods: Five NBS1 SNPs were selected based on their potential functional impact. A hospital-based cohort, comprising 481 patients with HBV-related HCC, 508 patients with chronic hepatitis B virus infection (CHB), and 581 healthy controls, was recruited for genotyping analysis.

Results: After quality control, four SNPs were successfully genotyped (rs10464867, rs1063053, rs 1805794, and rs709816), none of which were significantly associated with HCC or CHB compared with those of healthy controls. Similarly, the combined HBV-infected group (including the HCC and CHB groups) exhibited no significant associations with these SNPs compared with healthy controls. In contrast, comparison of the frequency of rs 1805794 between patients with CHB and those with HCC identified a significant association $(P=2.99 \mathrm{E}-03$, odds ratio $=1.31$, $95 \%$ confidence interval $=1.10-1.56$ ).

Conclusion: These findings suggest that, as a non-synonymous SNP, the rs $1805794 \mathrm{C} / \mathrm{G}$ polymorphism may play a role in the progression from CHB to HCC.

Keywords: NBS1, polymorphism, hepatitis B virus, Nijmegen breakage syndrome 1

\section{Introduction}

Primary liver cancer (PLC) is one of the most common causes of cancer death worldwide. ${ }^{1}$ Half of PLC cases are estimated to occur in China, ${ }^{2}$ and hepatocellular carcinoma (HCC) accounts for $\sim 90 \%$ of disease. The majority of HCC cases are diagnosed with advanced liver cancer, for which the 5-year survival rate is $<10 \%{ }^{3}$ In China, $\sim 80 \%$ of HCC patients have a history of hepatitis B virus (HBV) infection. ${ }^{4}$ The high HCC rates in parts of Asia and sub-Saharan Africa largely reflect the elevated prevalence of chronic hepatitis B virus infection (CHB), with $>8 \%$ of the populations in these regions chronically infected with the virus. ${ }^{5}$ The step from viral hepatitis and cirrhosis to HCC is considered as one of the most important processes in hepatocarcinogenesis; however, only a proportion of chronic HBV carriers develop HCC, indicating that host genetic factors may also be involved in the process; ${ }^{6}$ 
this hypothesis has been proven by several genome-wide association studies (GWASs). ${ }^{7-9}$ DNA damage occurs when harmful factors, such as HBV infection, aflatoxin, excessive drinking, and toxic metabolites, act on liver cell DNA, and the most detrimental form of DNA damage is DNA doublestrand breaks (DSBs). The important mechanisms of DSB repair in human beings are homologous recombination (HR) and non-homologous end joining (NHEJ), and the protein Nijmegen breakage syndrome 1 (NBS1) plays a vital role in identifying and repairing DSBs and maintaining genome stability in both pathways. ${ }^{10}$ As a DNA repair gene, NBS1 was first identified in the rare autosomal recessive inherited disease, Nijmegen breakage syndrome (NBS), which is characterized by elevated sensitivity to ionizing radiation, chromosome instability, abnormal cell cycle checkpoint, and a high frequency of malignancies. ${ }^{11}$

The results of a recent study showed that expression of NBS1 was significantly increased in liver tumors compared with corresponding adjacent nontumor tissue, and higher levels were detected in poorly differentiated $\mathrm{HCCs},{ }^{12}$ indicating that increased expression of NBS1 may have a significant role in liver cancer progression. The c-Myc protooncogene encodes a ubiquitous transcription factor involved in the control of cell growth and plays an essential role in carcinogenesis. NBS1 is a direct transcriptional target of c-Myc, linking the function of c-Myc to DNA DSB repair, and increased NBS1 can induce cell growth promotion. ${ }^{13}$ Increased NBS1 expression can promote the phosphorylation of Akt and increase the expression of the downstream mTOR protein. Activation of the Akt-mTOR-p70S6K pathway has a significant role in HCC progression through promotion of neoangiogenesis. ${ }^{14}$ Studies in head and neck cancer have generated similar results, indicating that increased expression of NBS1 is a significant prognostic marker of advanced head and neck squamous cell carcinoma and that its overexpression is an oncogenic event that contributes to transformation through activation of the PI3-kinase/Akt pathway. ${ }^{15}$

Functional genetic variation of NBS1 may influence the susceptibility to tumor development as a result of DNA repair deficiency. Genetic mutation of NBS1 can promote the occurrence of liver cancer in mice, ${ }^{16}$ and multiple single-nucleotide polymorphisms (SNPs) of NBS1 have been reported as associated with risk for several cancers, including those of the breast, ${ }^{17}$ nasopharynx, ${ }^{18}$ liver, ${ }^{19}$ colorectum, ${ }^{20}$ lung, ${ }^{21}$ and prostate, ${ }^{22}$ in addition to leukemia. ${ }^{23}$ However, to our best knowledge, no previous study has focused on the association between NBS1 SNPs and HBV-related HCC. We hypothesized that five SNPs in NBS1 may be positively associated with susceptibility among patients with HBV-related HCC, given their strong association with cancer susceptibility; therefore, we investigated associations between NBS1 SNPs and risk of HBV-related HCC.

\section{Patients and methods Study subjects}

Our study population was recruited in a population-based case-control study in Jinan, Shandong Province, and all subjects were ethnic Han Chinese. Patients with HBV-related HCC (HCC patients; $n=481)$, sex- and age ( \pm 5 years)-matched patients with $\mathrm{CHB}(\mathrm{n}=508)$, and sex- and age-matched healthy controls $(n=581)$ were recruited. HBV-related patients with HCC and CHB were recruited between January 2014 and December 2016 at the Affiliated Hospital of Shandong Academy of Medical Sciences (Jinan, Shandong Province, China). Control subjects were randomly selected from among individuals attending for regular physical examination at the same hospital during the same time period when patients were collected.

All HCC patients were diagnosed by pathological examination and computerized tomography and those with any another malignant tumor were excluded from the study. Patients with $\mathrm{CHB}$ and HBV-related HCC were defined according to the following serological parameters: HBsAg positive for $>6$ months, anti-HBs negative, and anti-HBc positive. All individuals were negative for antibodies to hepatitis $\mathrm{C}$ virus, hepatitis $\mathrm{D}$ virus, and human immunodeficiency virus. Healthy controls were individuals without any of the virus infections mentioned earlier. Individuals who smoked for $\geq 6$ months during their lifetime were considered as smokers and those who drank at least once per week for $>1$ year were classified as drinkers. This study was approved by the ethics committee of the Affiliated Hospital of Shandong Academy of Medical Sciences. Written informed consent was obtained from each subject at recruitment.

\section{SNP selection}

SNP markers were selected from the previous GWASs and candidate-gene association studies of NBS1 gene. ${ }^{19,21,24,25}$ SNPs were selected based on the following criteria: 1) previously reported to be associated with any kind of cancer; 2) rare variants (MAF <0.01) in the Chinese population were excluded; 3) all variants located in the coding region (synonymous [SYN] or non-synonymous [NSM]); 4) selection of potential regulatory elements, according to the Encyclopedia of DNA Elements (ENCODE) database (www.encodeproject.org); and 5) inclusion of only one 
SNP in high linkage disequilibrium (LD; $\left.r^{2}>0.8\right)$. Finally, five SNPs were selected for the subsequent validation analysis: rs10464867, rs1063053, rs1061302, rs1805794, and rs709816.

\section{Genotyping}

Genomic DNA samples were extracted from $500 \mu \mathrm{L}$ ethylenediaminetetraacetic acid (EDTA)-anticoagulated peripheral blood samples using a DNA extraction kit (LabAid 820, Zeesan Corp., Xiamen, Fujian Province, China), according to the manufacturer's instructions. DNA sample quantification was performed using a NanoDrop 2000 Spectrophotometer (Thermo Fisher Scientific, Waltham, MA, USA) and diluted to a final concentration of $20 \mathrm{ng} / \mu \mathrm{L}$.

Genotyping analysis of all samples was conducted using TaqMan custom genotyping assays on a 7500 Real-Time PCR System (Thermo Fisher Scientific), according to the manufacturer's instructions. All five SNPs were genotyped using TaqMan SNP Genotyping Assay kits on the GeneAmp 7500 Sequence Detection System using specific TaqMan probes. SNPs with a call rate $<90 \%$ or generating results that deviated from the Hardy-Weinberg equilibrium $(P<0.01)$ in control subjects were excluded from further analysis. Of the five SNPs included in the validation study, only one (rs1061302) was excluded from genotyping analysis because of the generation of inadequate cluster plots.

\section{Statistical analysis}

Two-sided chi-square tests were used to assess differences in the distribution of age, sex, smoking, and drinking status between patients and controls; values of $P<0.05$ were considered as statistically significant. Data analyses and summarizations were conducted using SPSS 19.0 for Windows (IBM Corporation, Armonk, NY, USA). The Cochran-Armitage trend test was used to analyze the genotype-phenotype association in each group using Plink v1.07 software (Center for Human Genetic Research, Massachusetts General Hospital and the Broad Institute of Harvard and MIT, Cambridge, MA, USA). Bonferroni correction for multiple SNP testing was performed with $P<0.0125$ considered as a significant association.

\section{Results}

The demographic and clinical characteristics of recruited patients are given in Table 1. The mean age of patients with $\mathrm{HCC}$ was 56 years, while that of patients with $\mathrm{CHB}$ and healthy controls were 51 and 53 years, respectively. In all, $79 \%$ of patients with HCC were males, while $77.4 \%$
Table I Demographic and clinical characteristics of patients with $\mathrm{HCC}$ and $\mathrm{CHB}$ and healthy controls

\begin{tabular}{|c|c|c|c|c|c|c|c|c|}
\hline \multirow[t]{2}{*}{ Characteristics } & \multicolumn{2}{|c|}{$\begin{array}{l}\text { HCC } \\
\text { cases } \\
(n=48 I)\end{array}$} & \multicolumn{2}{|c|}{$\begin{array}{l}\text { CHB } \\
\text { cases } \\
(n=508)\end{array}$} & \multicolumn{2}{|c|}{$\begin{array}{l}\text { Healthy } \\
\text { controls } \\
(n=581)\end{array}$} & \multirow{2}{*}{$\begin{array}{l}\text { HCC vs } \\
\text { CHB } \\
\text { P-value }\end{array}$} & \multirow{2}{*}{$\begin{array}{l}\text { HCC vs } \\
\text { controls } \\
P \text {-value }\end{array}$} \\
\hline & $\mathbf{n}$ & $\%$ & $\mathbf{n}$ & $\%$ & $\mathbf{n}$ & $\%$ & & \\
\hline Age (years) & & & & & & & 0.416 & 0.385 \\
\hline$\leq 56$ & 267 & 55.5 & 295 & 58.1 & 307 & 52.8 & & \\
\hline$>56$ & 214 & 44.5 & 213 & 41.9 & 274 & 47.2 & & \\
\hline Sex & & & & & & & 0.533 & 0.684 \\
\hline Male & 380 & 79.0 & 393 & 77.4 & 453 & 78.0 & & \\
\hline Female & 101 & 21.0 & 115 & 22.6 & 128 & 22.0 & & \\
\hline Smoking status & & & & & & & 0.302 & $<0.001$ \\
\hline Smoker & 306 & 63.6 & 307 & 60.4 & 282 & 48.5 & & \\
\hline Nonsmoker & 175 & 36.4 & 201 & 39.6 & 299 & 51.5 & & \\
\hline Drinking status & & & & & & & 0.728 & $<0.001$ \\
\hline Drinker & 294 & 61.1 & 305 & 60.0 & 232 & 39.9 & & \\
\hline Nondrinker & 187 & 38.9 & 203 & 40.0 & 349 & 60.1 & & \\
\hline
\end{tabular}

Abbreviations: $\mathrm{HCC}$, hepatocellular carcinoma; $\mathrm{CHB}$, chronic hepatitis $B$ virus infection.

and $78 \%$ of patients with CHB and healthy controls were males, respectively. There were no significant differences in age and sex among groups $(P>0.05)$. Of HCC patients with HBV, $63.6 \%$ and $61.1 \%$ had histories of smoking and drinking, respectively, which were significantly higher than that of healthy controls but not significantly different to that of patients with CHB.

Based on the previous publications and the criteria described in the "Patients and methods" section, we selected five candidate SNPs (rs10464867, rs1063053, rs1061302, rs1805794, and rs709816) for validation analysis. After quality control, data from $481 \mathrm{HCC}, 508 \mathrm{CHB}$, and 581 controls samples were available for validation analysis, and four SNPs (rs10464867, rs1063053, rs1805794, and rs709816) were successfully genotyped.

Genotyping results are presented in Table 2. First, the association of the SNPs was evaluated in patients with HCC or CHB compared with healthy controls. None of the four SNPs showed significant associations in these two comparisons. As the $\mathrm{HCC}$ and $\mathrm{CHB}$ group patients were all infected with $\mathrm{HBV}$, we then compared the HBV-infected group (consisting of the HCC and CHB groups combined) with healthy controls. Similarly, none of the four SNPs showed significant associations. Finally, we compared patients with $\mathrm{HCC}$ having HBV infection with those from the $\mathrm{CHB}$ group who had no HCC involvement. A significant association was identified with the NBS1 SNP rs1805794, $(P=2.99 \mathrm{E}-03)$ with an odds ratio of 1.31, suggesting a role for this SNP in the progression to HCC from CHB. The rs 1805794 SNP is 
Table 2 Association results of four candidate SNPs in HCC and CHB patients and healthy controls

\begin{tabular}{|c|c|c|c|c|c|c|c|c|}
\hline $\begin{array}{l}\text { SNP } \\
\text { information }\end{array}$ & $\begin{array}{l}\text { Minor allelel } \\
\text { major allele }\end{array}$ & Group & $\begin{array}{l}\text { Frequency } \\
\text { Cases }\end{array}$ & $\begin{array}{l}\text { Frequency } \\
\text { Controls }\end{array}$ & $P$-value & OR & L95 & U95 \\
\hline rsl805794 & $\mathrm{C} / \mathrm{G}$ & $\mathrm{HCC}$ vs control & $51.48 \%$ & $47.16 \%$ & $4.44 \mathrm{E}-02$ & 1.19 & 1.00 & 1.41 \\
\hline chr8: 90990479 & & $\mathrm{CHB}$ vs control & $44.80 \%$ & $47.16 \%$ & $1.90 \mathrm{E}-0 \mid$ & 0.89 & 0.75 & 1.06 \\
\hline \multirow[t]{2}{*}{ NSM } & & $\mathrm{HCC}+\mathrm{CHB}$ vs control & $47.11 \%$ & $47.16 \%$ & $9.77 \mathrm{E}-0 \mathrm{I}$ & 1.00 & 0.86 & 1.15 \\
\hline & & $\mathrm{HCC}$ vs $\mathrm{CHB}$ & $51.48 \%$ & $44.80 \%$ & $2.99 \mathrm{E}-03^{*}$ & 1.31 & 1.10 & 1.56 \\
\hline rs 10464867 & $\mathrm{~T} / \mathrm{C}$ & $\mathrm{HCC}$ vs control & $14.96 \%$ & $13.17 \%$ & $2.29 \mathrm{E}-0 \mathrm{I}$ & 1.16 & 0.91 & 1.48 \\
\hline chr8: 90945598 & & $\mathrm{CHB}$ vs control & $12.06 \%$ & $13.17 \%$ & $4.20 \mathrm{E}-0 \mathrm{I}$ & 0.90 & 0.69 & 1.17 \\
\hline \multirow[t]{2}{*}{ U3 } & & $\mathrm{HCC}+\mathrm{CHB}$ vs control & $13.48 \%$ & $13.17 \%$ & $8.03 \mathrm{E}-0 \mathrm{I}$ & 1.03 & 0.83 & 1.27 \\
\hline & & $\mathrm{HCC}$ vs $\mathrm{CHB}$ & $14.96 \%$ & $12.06 \%$ & $5.94 \mathrm{E}-02$ & 1.28 & 0.99 & 1.66 \\
\hline rsI063053 & $\mathrm{A} / \mathrm{G}$ & $\mathrm{HCC}$ vs control & $43.58 \%$ & $46.47 \%$ & $1.76 \mathrm{E}-0 \mathrm{|}$ & 0.89 & 0.75 & 1.05 \\
\hline chr8: 90947537 & & $\mathrm{CHB}$ vs control & $47.71 \%$ & $46.47 \%$ & $4.56 \mathrm{E}-0 \mathrm{I}$ & 1.07 & 0.90 & 1.27 \\
\hline \multirow[t]{2}{*}{ U3 } & & $\mathrm{HCC}+\mathrm{CHB}$ vs control & $46.53 \%$ & $46.47 \%$ & $9.74 \mathrm{E}-0 \mathrm{I}$ & 1.00 & 0.87 & 1.16 \\
\hline & & $\mathrm{HCC}$ vs $\mathrm{CHB}$ & $43.58 \%$ & $47.71 \%$ & $6.52 \mathrm{E}-02$ & 0.85 & 0.71 & 1.01 \\
\hline rs709816 & $\mathrm{A} / \mathrm{G}$ & $\mathrm{HCC}$ vs control & $32.58 \%$ & $30.12 \%$ & 2.|7E-0| & 1.12 & 0.94 & 1.34 \\
\hline chr8: 909677।I & & $\mathrm{CHB}$ vs control & $30.35 \%$ & $30.12 \%$ & $9.48 \mathrm{E}-0 \mathrm{I}$ & 0.99 & 0.82 & 1.21 \\
\hline \multirow[t]{2}{*}{ SYN } & & $\mathrm{HCC}+\mathrm{CHB}$ vs control & $30.53 \%$ & $30.12 \%$ & $8.12 \mathrm{E}-0 \mid$ & 1.02 & 0.87 & 1.19 \\
\hline & & $\mathrm{HCC}$ vs $\mathrm{CHB}$ & $32.58 \%$ & $30.35 \%$ & $2.87 \mathrm{E}-0 \mathrm{I}$ & 1.11 & 0.92 & 1.34 \\
\hline
\end{tabular}

Note: $* P<0.0125$ was considered as significant (Bonferroni correction for four tested SNPs).

Abbreviations: SNP, single-nucleotide polymorphism; HCC, hepatocellular carcinoma; CHB, chronic hepatitis B virus infection; OR, odds ratio; NSM, non-synonymous; U3, 3'-untranslated region; SYN, synonymous; L95, lower-tail 95\%; U95, upper-tail 95\%.

located in the fifth exon of the NBSI gene and encodes an NSM substitution of glutamate (Glu) to glutamine (Gln).

\section{Discussion}

In this study, we investigated the association between NBS1 polymorphisms and HBV-related HCC using a case-control study to identify genetic factors that confer individual susceptibility to HBV-related HCC. The results showed that the functional polymorphism, rs $1805794 \mathrm{C} / \mathrm{G}$ in $N B S 1$, was associated with an increased risk for developing HBV-related HCC among CHB patients. A Chinese study by Huang et a ${ }^{19}$ previously investigated the association between genetic polymorphisms in $N B S 1$ and HCC risk, analyzing genotypes in 865 patients with $\mathrm{HCC}$ and 900 cancer-free controls, and found that the rs $1805794 \mathrm{C} / \mathrm{G}$ polymorphism in NBS1 was associated with an increased risk of developing HCC in an allele dose-response manner. There was no independent CHB group in that study; however, interestingly, $83.1 \%$ of patients with HCC had HBV infection and 13\% of controls had HBV infection; hence, the conclusions of that report are consistent with those of our study. In China, HBV infection is the most important risk factor for HCC, and HCC usually occurs in patients with HBV-associated cirrhosis. ${ }^{4}$ In the US and several other Western developed countries, alcoholrelated cirrhosis is thought to account for the majority of liver cancers. ${ }^{1}$ Harmful factors, such as HBV infection and alcohol abuse, cause DNA and cell damage in the liver. If such damage is not repaired in a timely manner, the accumulation of abnormalities may lead to liver cancer. In patients with CHB, integration of HBV into the host genome has been found to lead to novel fusion transcripts and/or local genomic instability, resulting in secondary deletions, rearrangements, duplications, or inversions of the host and/or viral genomic sequences. ${ }^{26}$

The NBS1 gene, mapping to human chromosome 8q21, is $\sim 50 \mathrm{~kb}$ in length, including 16 exons, and encodes the 754 amino acid (AA) protein NBS1 (p95). ${ }^{27} \mathrm{NBS} 1$ is an important component of the MRE-RAD50-NBS1 (MRN) complex that has a critical role in DNA DSB repair. MRN functions as a sensor for DNA damage in NHEJ and participates in DNA repair and the intra-S-phase cell cycle checkpoint in HR. ${ }^{28}$ It binds directly to phosphorylated histone, H2AX, located around DSBs, to maintain genomic stability and prevent cells from undergoing telomeric fusion. ${ }^{29}$ The NBS1 protein has three major functional regions: the N-terminus (1-196 AAs), the central region (278-343 AAs), and the C-terminus (665-693 AAs) ${ }^{28}$ The N-terminal region contains a forkhead-associated (FHA) domain (24-108 AAs) and two breast cancer carboxy-terminus (BRCT) domains (BRCT1: 114-183 AAs and BRCT2: 221-291 AAs). The FHA and BRCT domains are widely conserved in eukaryotic nuclear proteins related to cell cycle checkpoints or DNA repair, and the central region functions in signal transduction in response to damage. ${ }^{27}$ The $\mathrm{C}$-terminal region contains a binding site for the MRN, ${ }^{28}$ which is crucial for detection and repair of DSBs via the NHEJ and HR pathways. 
Animal experiments have provided experimental evidence that NBS1 heterozygosity predisposes cells to malignancy, most likely because of chromosomal instability and defects in DNA repair. In the study, heterozygous knockout (NBS1 \pm ) mice developed a wide array of solid tumors, including those of the liver, mammary gland, prostate, and lung, in addition to lymphomas. ${ }^{16}$ Other studies have demonstrated that the overexpression of NBS1 is associated with the occurrence and progression of some cancers, including head and neck squamous cell carcinomas, ${ }^{15}$ prostate cancer, ${ }^{30}$ liver cancer, ${ }^{31}$ and esophageal malignancies. ${ }^{32}$ The study showed that overexpressed NBS1 interacts directly, through its $\mathrm{C}$-terminal region, with the $\mathrm{N}$-terminal domain (1-108 AAs) of the $\mathrm{p} 110 \alpha$ catalytic subunit of PI3-kinase to stimulate PI3-kinase activity, ${ }^{33}$ and the activated PI3K/ Akt pathway can promote angiogenesis, which is involved in tumor development. ${ }^{34}$

As an NSM SNP, the NBS1 rs $1805794 \mathrm{C} / \mathrm{G}$ polymorphism leads to a substitution of Glu with Gln. This SNP site is in the BRCT domain, through which NBS1 can interact with BRCA1 (one of two familial breast cancers' mutated genes) to form the BRCA1-associated genome surveillance complex (BASC), ${ }^{35}$ which is responsible for the recognition and repair of aberrant DNA. Since either one or two missense changes in the dominant genetic model may affect the function of NBS1 and interfere with protein-protein interaction, ${ }^{36}$ the $\mathrm{rs} 1805794 \mathrm{C} / \mathrm{G}$ polymorphism could potentially affect the function of the NBS1 protein and the protein-protein interaction between NBS1 and BRCA1. The NBS1 rs1805794 C/G polymorphism has frequently been investigated in different cancer types and geographical areas, and its variant genotype is associated with increased morbidity of several cancers, including nasopharyngeal carcinoma, ${ }^{18}$ hepatic cancer, ${ }^{19}$ acute lymphoblastic leukemia, ${ }^{37}$ lung cancer, ${ }^{38}$ and prostate cancer. ${ }^{22}$ The findings of our present study suggest that the rs 1805794 $\mathrm{C} / \mathrm{G}$ polymorphism also increases the risk of $\mathrm{HCC}$ in patients who have been infected with $\mathrm{HBV}$, rather than increasing the risk of HBV infection in individuals, and that the rs 1805794 C/G polymorphism may affect the DNA damage repair function of NBS1 in hepatitis-infected liver cells, increasing the risk of $\mathrm{HCC}$.

Along with NBS1, RAD52 is another key gene involved in the HR pathway, and the association between its genetic polymorphisms and HBV-related HCC has also been investigated. ${ }^{39}$ In that study, genotypes were determined in two independent case-control cohorts from two regions of China. The results indicated that the RAD52 rs7963551 A/C polymorphism contributes to susceptibility to developing HBV-related HCC. Furthermore, genotype-phenotype correlation analyses were carried out using 44 liver tissue samples, and rs $7963551 \mathrm{CC}$ or AC genotypes were identified as associated with a statistically significant increase in $R A D 52$ mRNA expression, consistent with a functional correlation between allelic regulation of RAD52 expression and the rs7963551 SNP in tumor cells.

Moreover, along with $N B S 1$, another direct transcriptional target gene of c-Myc, EPB41, is also a HCC susceptibility gene; the same researchers identified the EPB41 SNP rs $157224 \mathrm{G} / \mathrm{T}$ as associated with susceptibility to HBVrelated $\mathrm{HCC}$ in Chinese populations. Binding site prediction and in vivo and vitro experiments to determine the function of this SNP revealed that rs $157224 \mathrm{G} / \mathrm{T}$ affected binding of the transcription factor, c-Myc, to a site involved in the regulation of the EPB41 gene. ${ }^{40}$ The current study has some limitations. As it is a hospital-based study, there may be inherent selection bias. Moreover, the statistical power of our study is limited by the sample size, particularly for statistical analyses of gene-environment interactions; however, the fact that the genotype frequencies among controls fitted the Hardy-Weinberg equilibrium suggests that subject selection was sufficiently random. Finally, based on relevant publications, ${ }^{39,40}$ further experiments are required to test the influence of the $\mathrm{rs} 1805794 \mathrm{C} / \mathrm{G}$ polymorphism on NBS1 regulation.

\section{Conclusion}

Our study suggests that, as an NSM substitution, the rs $1805794 \mathrm{C} / \mathrm{G}$ polymorphism in NBS1 may be a genetic susceptibility factor for the risk of HBV-related HCC developing from $\mathrm{CHB}$ in a Chinese population. These findings require verification using larger, preferably populationbased, case-control studies and well-designed mechanistic experiments.

\section{Acknowledgment}

This work was supported by grants from the Youth Innovation Program of the Affiliated Hospital of Shandong Academy of Medical Sciences Technology Plan (No 2017-02), the Innovation Project of Shandong Academy of Medical Sciences, Shandong Provincial Science and Technology Development Plan (No 2015GSF121040), the Shandong Provincial Medicine and Health Science Technology Development Plan (Nos 2015WS0149, 2015WS0197, 2013WS0145, 2015WS0228), and the Science and Technology Development Plan of Jinan (No 201401253). 


\section{Disclosure}

The authors report no conflicts of interest in this work.

\section{References}

1. Jemal A, Bray F, Center MM, Ferlay J, Ward E, Forman D. Global cancer statistics. CA Cancer J Clin. 2011;61(2):33-64.

2. Chen W, Zheng R, Baade PD, et al. Cancer statistics in China, 2015. CA Cancer J Clin. 2016;66(2):115-132.

3. Fitzmorris P, Shoreibah M, Anand BS, Singal AK. Management of hepatocellular carcinoma. J Cancer Res Clin Oncol. 2015;141(5): 861-876.

4. Tanaka M, Katayama F, Kato H, et al. Hepatitis B and C virus infection and hepatocellular carcinoma in China: a review of epidemiology and control measures. J Epidemiol. 2011;21(6):401-416.

5. McGlynn KA, Petrick JL, London WT. Global epidemiology of hepatocellular carcinoma: an emphasis on demographic and regional variability. Clin Liver Dis. 2015;19(2):223-238.

6. Yu MW, Chang HC, Liaw YF, et al. Familial risk of hepatocellular carcinoma among chronic hepatitis B carriers and their relatives. J Natl Cancer Inst. 2000;92(14):1159-1164.

7. Jiang DK, Sun J, Cao G, et al. Genetic variants in STAT4 and HLA-DQ genes confer risk of hepatitis B virus-related hepatocellular carcinoma. Nat Genet. 2013;45(1):72-75.

8. Liu M, Jiang L, Guan XY. The genetic and epigenetic alterations in human hepatocellular carcinoma: a recent update. Protein Cell. 2014; 5(9):673-691.

9. Kim YJ, Kim HY, Lee JH, et al. A genome-wide association study identified new variants associated with the risk of chronic hepatitis B. Hum Mol Genet. 2013;22(20):4233-4238.

10. Williams GJ, Lees-Miller SP, Tainer JA. Mre11-Rad50-Nbs1 conformations and the control of sensing, signaling, and effector responses at DNA double-strand breaks. DNA Repair. 2010;9(12):1299-1306.

11. Wolska-Kuśnierz B, Gregorek H, Chrzanowska K, et al; Inborn Errors Working Party of the Society for European Blood and Marrow Transplantation and the European Society for Immune Deficiencies. Nijmegen breakage syndrome: clinical and immunological features, long-term outcome and treatment options - a retrospective analysis. J Clin Immunol. 2015;35(6):538-549.

12. Yan W, Man L, Jiang L, et al. Clinical significance of increased expression of Nijmegen breakage syndrome gene (NBS1) in human primary liver cancer. Hepatol Int. 2014;8(2):250-259.

13. Chiang YC, Teng SC, Su YN, Hsieh FJ, Wu KJ. c-Myc directly regulates the transcription of the NBS1 gene involved in DNA double-strand break repair. J Biol Chem. 2003;278(21):19286-19291.

14. Li W, Tan D, Zhang Z, Liang JJ, Brown RE. Activation of Akt-mTORp70S6K pathway in angiogenesis in hepatocellular carcinoma. Oncol Rep. 2008;20(4):713-719.

15. Yang MH, Chiang WC, Chou TY, et al. Increased NBS1 expression is a marker of aggressive head and neck cancer and overexpression of NBS1 contributes to transformation. Clin Cancer Res. 2006;12(2):507-515.

16. Dumonjones V, Frappart PO, Tong WM, et al. Nbn heterozygosity renders mice susceptible to tumor formation and ionizing radiationinduced tumorigenesis. Cancer Res. 2003;63(21):7263-7269.

17. Wu Z, Wang P, Song C, et al. Evaluation of miRNA-binding-site SNPs of MRE11A, NBS1, RAD51 and RAD52 involved in HRR pathway genes and risk of breast cancer in China. Mol Genet Genomics. 2015;290(3):1141-1153.

18. Zheng J, Zhang C, Jiang L, et al. Functional NBS1 polymorphism is associated with occurrence and advanced disease status of nasopharyngeal carcinoma. Mol Carcinog. 2011;50(9):689-696.

19. Huang MD, Chen XF, Xu G, et al. Genetic variation in the NBS1 gene is associated with hepatic cancer risk in a Chinese population. DNA Cell Biol. 2012;31(5):678-682.
20. Li JT, Zhong BY, Xu HH, et al. Associations between NBS1 polymorphisms and colorectal cancer in Chinese population. PLoS One. 2015; 10(7): 0132332.

21. Yang T, Chang PY, Park SL, et al. Tobacco smoking, NBS1 polymorphisms, and survival in lung and upper aerodigestive tract cancers with semi-Bayes adjustment for hazard ratio variation. Cancer Causes Control. 2014;25(1):11-23.

22. Silva J, Teixeira AL, Lobo F, Maurício J, Medeiros R. DNA repair system and prostate cancer progression: the role of NBS1 polymorphism (rs1805794). DNA Cell Biol. 2012;31(7):1182-1186.

23. Li N, Xu Y, Zheng J, et al. NBS1 rs1805794G $>$ C polymorphism is associated with decreased risk of acute myeloid leukemia in a Chinese population. Mol Biol Rep. 2013;40(5):3749-3756.

24. Sun $P$, Du J, Zhu X, et al. Genetic variation in the $3^{\prime}$-untranslated region of NBN gene is associated with gastric cancer risk in a Chinese population. PLoS One. 2015;10(9):e0139059.

25. Park SL, Bastani D, Goldstein BY, et al. Associations between NBS1 polymorphisms, haplotypes and smoking-related cancers. Carcinogenesis. 2010;31(7):1264-1271.

26. Murakami Y, Saigo K, Takashima H, et al. Large scaled analysis of hepatitis B virus (HBV) DNA integration in HBV related hepatocellular carcinomas. Gut. 2005;54(8):1162-1168.

27. Kobayashi J, Antoccia A, Tauchi H, Matsuura S, Komatsu K. NBS1 and its functional role in the DNA damage response. DNA Repair. 2004; 3(8-9):855-861.

28. Komatsu K. NBS1 and multiple regulations of DNA damage response. J Radiat Res. 2016;57(suppl 1):i11-i17.

29. Saito Y, Fujimoto H, Kobayashi J. Role of NBS1 in DNA damage response and its relationship with cancer development. Transl Cancer Res. 2013;2(3):178-189.

30. Berlin A, Lalonde E, Sykes J, et al. NBN gain is predictive for adverse outcome following image-guided radiotherapy for localized prostate cancer. Oncotarget. 2014;5(22):11081-11090.

31. Wang Y, Li M, Long J, et al. Clinical significance of increased expression of Nijmegen breakage syndrome gene (NBS1) in human primary liver cancer. Hepatol Int. 2014;8(2):250-259.

32. Kuo KT, Chou TY, Hsu HS, Chen WL, Wang LS. Prognostic significance of NBS1 and snail expression in esophageal squamous cell carcinoma. Ann Surg Oncol. 2012;19(suppl 3):549-557.

33. Chen YC, Chiang HY, Yang MH, et al. Activation of phosphoinositide 3-kinase by the NBS1 DNA repair protein through a novel activation motif. J Mol Med. 2008;86(4):401-412.

34. Wang JQ, Chen JH, Chen YC, et al. Interaction between NBS1 and the mTOR/Rictor/SIN1 complex through specific domains. PLoS One. 2013;8(6):e65586.

35. Yuan J, Chen J. MRE11-RAD50-NBS1 complex dictates DNA repair independent of H2AX. J Biol Chem. 2010;285(2):1097-1104.

36. Tauchi H. Positional cloning and functional analysis of the gene responsible for Nijmegen breakage syndrome, NBS1. J Radiat Res. 2000; 41(1):9-17.

37. Jiang L, Liang J, Jiang M, et al. Functional polymorphisms in the NBS1 gene and acute lymphoblastic leukemia susceptibility in a Chinese population. Eur J Haematol. 2011;86(3):199-205.

38. Fang W, Qiu F, Zhang L, et al. The functional polymorphism of NBS1 p.Glu185Gln is associated with an increased risk of lung cancer in Chinese populations: case-control and a meta-analysis. Mutat Res. 2014;770:61-68.

39. Li Z, Guo Y, Zhou L, et al. Association of a functional RAD52 genetic variant locating in a miRNA binding site with risk of HBV-related hepatocellular carcinoma. Mol Carcinog. 2015;54(9):853-858.

40. Yang X, Yu D, Ren Y, et al. Integrative functional genomics implicates EPB41 dysregulation in hepatocellular carcinoma risk. Am J Hum Genet. 2016;99(2):275-286. 
OncoTargets and Therapy

\section{Publish your work in this journal}

OncoTargets and Therapy is an international, peer-reviewed, open access journal focusing on the pathological basis of all cancers, potential targets for therapy and treatment protocols employed to improve the management of cancer patients. The journal also focuses on the impact of management programs and new therapeutic agents and protocols on

patient perspectives such as quality of life, adherence and satisfaction The manuscript management system is completely online and includes a very quick and fair peer-review system, which is all easy to use. Visit http://www.dovepress.com/testimonials.php to read real quotes from published authors.

Submit your manuscript here: http://www.dovepress.com/oncotargets-and-therapy-journal 